\title{
Kidney Tumor, Lower Pole
}

National Cancer Institute

\section{Source}

National Cancer Institute. Kidney Tumor, Lower Pole. NCI Thesaurus. Code C159237.

A tumor located in the lower pole of the kidney. 